\title{
PENGARUH KOMITMEN ORGANISASI DALAM MEMEDIASI KEPEMIMPINAN TRANSFORMASIONAL TERHADAP PERILAKU INOVATIF TENAGA PEMASARAN PT. TIRA AUSTENITE
}

\author{
Ardi Kusmara *) \\ *) Dosen Fakultas Ekonomi Universitas Darma Persada Jakarta Timur \\ e-mail: ardikusmara66@gmail.com
}

\begin{abstract}
This research aimed to to investigated the role organizational commitment in mediating the effect of transformational on innovative behavior. Survey method used in this research. Amount of the samples in this research are 67 sales of at PT. Tira Austenite that selected randomly. The data were collecting through questionnaire and analyzed by using path analysis. The results of the research can be concluded that: transformational leadership and organizational commitment have a direct effect on innovative behaviour; transformational have a direct effect on sales innovative behavior and transformational leadership have an indirect effect on innovative behaviors through organizational commitment.
\end{abstract}

Keywords: Transformational leadership, organizational commitment, innovative behavior

\section{PENDAHULUAN}

Dunia saat ini mengalami disrupsi yang ditandai dengan perubahan sangat cepat pada berbagai bidang kehidupan. Dalam situasi lingkungan yang bergerak dinamis, maka implikasinya pada bidang usaha adalah terjadinya persaingan yang ketat. Situasi seperti ini tidak bisa disikapi dengan berdiam diri jika perusahaan atau organisasi ingin tetap survive, tetapi harus direspon dengan kecepatan beradaptasi dengan dibuktikan melalui inovasi.

Inovasi adalah prasyarat bagi perusahaan untuk berkembang dan yang gagal berinovasi akan kalah dalam persaingan (Tidd, Bessant, \& Pavitt, 2005). Inovasi organisasi dimulai pada level individu, sehingga perilaku inovatif anggota organisasi atau karyawan sangat menentukan inovasi organisasi. Perilaku inovasi adalah kunci untuk inovasi organisasi (Park \& Jo, 2018). Dengan demikian, perilaku inovatif menjadi kunci dalam memperkuat daya saing perusahaan (Gkorezis, 2016). Dengan demikian kunci utama dalam mencapai kesuksesan perusahaan saat ini adalah mendorong sumber daya manusia organisasi agar memiliki perilaku inovatif yang menjadi sumber inovasi organisasi.

PT. Tira Austenite yang bergerak bidang penjualan special steel, gas industri, dan manufacturing Bronze juga merasakan dampak disrupsi yang ditandai dengan persaingan yang semakin berat. Dalam situasi seperti ini, PT. Tira Austenite juga memposisikan SDM sebagai faktor strategis dalam pengembangan perusahaan sehingga terus berusaha meningkatkan kualitasnya agar mampu menunjukkan kinerja yang optimal. Salah satu divisi yang menjadi ujung tombak perusahaan adalah pemasaran dan tenaga pemasaran merupakan pilar penting perusahaan karena perannya secara langsung dalam menentukan profitabilitas perusahaan.

Tenaga pemasaran di PT. Tira Austenite saat ini perlu mendapatkan perhatian karena kinerjanya yang kurang optimal. Hal ini ditunjukkan dengan kinerja penjualan selama lima tahun terakhir yang tidak mencapai target dengan tingkat capaian rata-rata setiap $86,6 \%$ setiap tahun. 
Fakta ini sekaligus menunjukkan bahwa belum ada inovasi-inovasi signifikan yang dilakukan para tenaga penjualan dalam menjalankan tugasnya, sehingga tidak ada terobosan-terobosan baru yang dapat meningkatkan hasil penjualannya.

Perilaku inovatif individu merupakan faktor yang tidak berdiri sendiri, tetapi dipengaruhi oleh faktor-faktor lainnya. Secara teoretik faktor yang mempengaruhi perilaku inovatif yaitu kepemimpinan transformasional dan komitmen organisasi. Terkait dengan hal itu, maka penelitian ini bertujuan untuk menganalisis pengaruh kepemimpinan transformasional terhadap perilaku inovatif tenaga pemasaran dengan komitmen organisasi sebagai mediator pada PT. Tira Austenite.

\section{LANDASAN TEORI}

\section{Perilaku Inovatif}

Secara konsep, Pedraza et al. (2012) menjelaskan perilaku inovatif, "innovative behavior as attitudes about the new changes or improvements the production process, both in manufacturing and service firms, in order to make a profit within the internal structure of the organization in a business network, or as a result of the core business". Perilaku inovatif adalah sikap tentang perubahan baru atau proses perbaikan produksi, baik di bidang manufaktur dan perusahaan layanan, dalam rangka membuat keuntungan dalam struktur internal organisasi dalam jaringan bisnis, atau sebagai hasil dari bisnis inti.

West dan Farr dalam Kleysen dan Street (2001) menguraikan makna perilaku inovatif yaitu "innovative behavior is defined as all individual actions directed at the generation, introduction and or application of benefecial novelty at any organization level. Such benefecial novelty might include the development of new product ideas or technologies, changes in administratifve procedures aimed at improving work relations or the application of new ideas or technologies to work processes intended to significantly enhance their efficiency and effectiveness. " Perilaku inovatif adalah tindakan indvidu yang diarahkan untuk menghasilkan, memperkenalkan atau mengaplikasikan temuan baru yang menguntungkan pada setiap tingkatan organisasi. Temuan baru seperti meliputi pengembangan ide produk baru atau teknologi, mengubah prosedur administratif yang ditujukan untuk meningkatkan hubungan kerja atau mengaplikasikan ide atau teknologi baru untuk proses kerja yang ditujukan untuk meningkatkan secara signifikan efisien dan efektivitas.

Janssen dalam Shih dan Susanto (2011) menjelaskan konsep perilaku inovatif adalah, "innovative work behavior asintentional creation, introduction and application of new ideas within a work role, group or organization, in order to benefit role performance, the group, or the organization." Perilaku inovasi adalah penciptaan yang disengaja, pengenalan dan penerapan ide-ide baru dalam sebuah peran kerja kelompok atau organisasi agar menguntungkan peran kinerja kelompok atau organisasi.

Perilaku inovatif merupakan inovasi yang dilakukan secara individual. Menurut Scott dan Bruce yang dikutip Cingöz dan Akdo (2011), inovasi individual dimulai dengan penurunan ide, yaitu produksi dan penggunaan ide-ide baru dalam beberapa domain. Tahapan proses inovasi selanjutnya adalah promosi ide terhadap penggabungan potensial. Sekali individu menghasilkan ide, maka individu tersebut terikat ke dalam aktivitas sosial menemukan teman, pendukung, dan sponsor atau membangun koalisi dari pendukung yang memberikan kekuatan penting untuk merealisasikan ide. Tugas terakhir dari proses inovasi berhubungan realisasi ide dengan memproduksi sebuah prototipe atau model inovasi yang dapat dirasakan dan puncaknya diaplikasikan dalam peran kerja, kelompok, atau organisasi secara keseluruhan.

Perilaku inovatif individu dapat diukur melalui beberapa indikator. Kleysen 
dan Street (2001) menunjukkan lima dimensi untuk mengukur perilaku inovatif, yaitu: eksplorasi peluang, generativitas, investigas iformatif, memperjuangkan, dan aplikasi.

Berdasarkan uraian konsep di atas, dapat disintesiskan bahwa perilaku inovatif adalah tindakan indvidu yang diarahkan untuk melakukan perubahan dan perbaikan dalam proses penyelesain pekerjaan untuk memperoleh hasil kerja yang lebih baik diukur dengan indikator: mencari cara kerja yang lebih efektif, mengusulkan programprogram kerja baru, memberikan masukan untuk menyelesaikan masalah organisasi, mengumpulkan informasi terkini terkait pekerjaan, mengidentifikasi kelemahan kerja, mendiskusikan ide dengan teman dan atasan, dan memperjuangkan ide.

\section{Kepemimpinan Transformasional}

"Leaders who make decisions by taking into account the social situation of the group / organization, will be felt as a joint decision which is a shared responsibility in implementing it"'(Muhammad Farhan; Muhammad Faisal 2021)

Gibson, Ivancevich, Donnelly, dan Kanopaske. Gibson et al. (2012) memberikan definisi kepemimpinan transformasional yaitu, "transformational leadership is the ability to inspire and motivate followers to achieve results greater than originally planned for internal rewards". Kepemimpinan transformasional adalah kemampuan untuk menginspirasi dan memotivasi bawahan untuk mencapai hasil yang lebih besar dibandinggkan perencanaan awal untuk imbalan internal.

Griffin dan Moorhead (2014) menjelaskan, "transformational leadership refers to the set of abilities that allows the leader to recognize the need for change, to create a vision to guide that change, and to execute the change effectively". Kepemimpinan transformasional adalah seperangkat kemampuan yang memungkinkan pemimpin untuk mengenali kebutuhan perubahan, menciptakan visi untuk membimbing perubahan, dan untuk melaksanakan perubahan secara efektif.

Hitt, Miller, dan Colella (2011) menjelaskan

transformasional

teadership is a lead kepemimpinan "transformational involves motivating followers to do more than expected, to continuously develop and grow, to increase self confidence, and to place the interests of the unit ororganization before their own."

Kepemimpinan transformasional menurut pengertian di

$$
\text { atas adalah pendekatan }
$$

kepemimpinan yang memotivasi bawahan untuk melakukan lebih

dari yang diharapkan, untuk terus menerus tumbuh, untuk meningkatkan kepercayaan diri dan untuk menempatkan kepentingan unit atau organisasi sebelum kepentingannya sendiri. Beberapa hal yang dilakukan oleh seorang pemimpin

transformasional menurut Bertocci (2009) yaitu:

1). Mencaripeluang,

2). Bereksperimen dan mengambilrisiko,

3). Mengembangkan visi,

4.) Mendaftar orang lain, 5). Memperkuat kolaborasi,

6). Menguatkan orang lain

7). Memberikan contoh,

8). Merencanakankemenangan kecil,

9). Mengaitkan imbalandengan

kinerja,

10). Merayakan

kemenangan.

Pemimpin yang menerapkan kepemimpinan transformasional menurut Bass dan Avolio sebagaimana dikutip Rowe dan Guerrero (2011) menunjukkan empat dimensi kepemimpinan transformasional, yaitu: pengaruh ideal atau kharisma, motivasi inspirasional, stimulasi intelektual, dan konsiderasi individual.

Dari uraian di atas, maka dapat disintesiskan kepemimpinan transformasional adalah pola prilaku kemampuan mempengaruhi seorang 


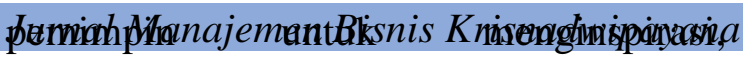
memotivasi dan mengenali kebutuhan perubahan bawahan sehingga memungkinkan bawahan melakukan perubahan ke arah yang lebih untuk mencapai hasil yang lebih besar dengan indikator: pengaruh idealisme, motivasi inspirasional, stimulasi intelektual, dan konsiderasi individual.

\section{Komitmen Organisasi}

Muchinsky (2006) menjelaskan tentang konsep komitmen organisasi yaitu, "organizational commitment refers to th degree to which an employee feels a sense of allegiance to his or her employer". Komitmen organisasi adalah tingkat sejauhmana karyawan merasa setia terhadap organisasi yang mempekerjakannya. Jex (2002) mengungkapkan tentang konsep komitmen organisasi, "organizational commitment difined as the extent to which employees are dedicated to their employing organization and are willing to work on its behalf, and the likelihood that they will maintain membership". Komitmen organisasi adalah sejauh mana karyawan berdedikasi untuk organisasi yang mempekerjakannya dan bersedia untuk bekerja atas nama organisasi, serta mempertahankan keanggotaannya.

Selanjutnya Porter et al. sebagaimana dikutip Armstrong (2009) menguraikan bahwa komitmen organisasi adalah pengikatan (attachment) dan loyalitas (loyalty), yang merupakan kekuatan relatif dari identifikasi individu bersama dan keterlibatannya dengan organisasi. Kekuatan relatif tersebut meliputi tiga faktor, yaitu: 1). Keinginan yang kuat untuk mempertahankan keanggotaannya dalam organisasi, 2). Kepercayaan yang kuat dan penerimaan atas nilai-nilai dan tujuan organisasi, dan 3). Kesediaan untuk melakukan upaya-upaya besar atas nama organisasi.

Allen dan Meyer yang dikutip Levy (2010) membagi komitmen ke dalam tiga bentuk, yang pertama adalah komitmen afektif, yaitu keterikatan terhadap organisasi dengan ciri keyakinan yang kuat dan penerimaan atas nilai dan tujuan organisasi, kesediaan mengeluarkan usaha atas nama This work is licensed under a Creative Commons Attribution-Non Ciptaan disebarluaskan di bawah Lisensi Creative Commons Atribusi-BerbagiSerupa 4.0 Internasional. organisasi, dan kehendak yatreglikikasmertrak

mempertahankan keanggotaannya. Kedua, komitmen kontinuasi, yaitu keterikatan terhadap organisasi sebagai sebuah fungsi dari apa yang karyawan telah investasikan di dalam organisasi. Ketiga, komitmen normatif, berkenaan dengan keterikatan terhadap organisasi yang menunjukkan kewajiban seseorang untuk terus bekerja di dalam organisasi.

Berdasarkan penjelasan di atas, dapat disimpulkan bahwa komitmen organisasi adalah ikatan dan rasa identifikasi yang memperlihatkan derajat hubungan anggota organisasi terhadap organisasinya dengan indikator: keinginan untuk bertahan sebagai anggota organisasi, penerimaan atas nilai dan tujuan organisasi, kesiapan untuk berusaha demi kemajuan organisasi, ketaatan terhadap peraturan, loyalitas, dan keterlibatan dalam organisasi.

\section{Hipotesis}

Hipotesis dalam penelitian ini dirumuskan sebagai berikut: 1). Terdapat pengaruh langsung kepemimpinan transformasional terhadap perilaku inovatif tenaga pemasaran. 2). Terdapat pengaruh langsung kepemimpinan transformasional terhadap komitmen organisasi tenaga pemasaran. 3). Terdapat pengaruh langsung komitmen organisasi terhadap perilaku inovatif tenaga pemasaran. 4). Terdapat pengaruh langsung kepemimpinan transformasional terhadap perilaku inovatif melalui komitmen organisasi

\section{METODE PENELITIAN}

Penelitian ini menggunakan pendekatan kuantitatif melalui metode survei dengan menggunakan teknik analisis jalur (path analysis). Populasi penelitian ini adalah tenaga pemasaran pada PT. Tira Austenite yang berjumlah 80 orang. Sampel penelitian sebanyak 67 tenaga pemasaran yang ditetapkan dengan rumus Slovin dengan tingkat kesalahan 5\% dan teknik pengambilan sampel menggunakan acak sederhana.

Teknik pengumpulan data menggunakan kuesioner skala Likert 1-5. 
dan reliabilitasnya. Hasil perhitungan validitas variabel kepemimpinan transformasional diketahui dari 32 butir pernyataan terdapat 2 butir yang tidak valid dengan koefisien Alpha $=0,952>0,7$. Variabel komitmen organisasi diketahui dari 30 butir pernyataan

terdapat satu butir yang tidak valid dengan koefisien Alpha $=0,946>0,7$. Sementara untuk variabel perilaku inovatif diketahui dari 30 butir pernyataan terdapat satu butir yang tidak valid koefisien Alpha $=0,973>$ 0,7 .

Data yang diperoleh dari hasil penelitian selanjutnya dianalisis dengan menggunakan analisis statistik deskriptif dan statistik inferensial. Analisis statistik deskriptif dilakukan dengan menghitung nilai rata-rata, median, modus, standar deviasi, varians, skor maksimum dan minimum,serta dilengkapi dengan distribusi frekuensi dan histrogram. Sementara untuk statistik inferensial menggunakan analisis jalur (path analysis) dan dilengkapi dengan model persamaan struktural.

\section{HASIL DAN PEMBAHASAN}

\section{Hasil Penelitian}

Skor yang diperoleh dari hasil penyebaran kuesioner dihitung statistik deksriptif yang meliputi skor terendah, skor tertinggi, jangkauan, rataan, standar deviasi, dan varians yang hasilnya disajikan pada tabel berikut.

Tabel 1: Statistik Deskriptif

\begin{tabular}{lccc}
\hline Statistik Deskriptif & $\begin{array}{c}\text { Kepemimpinan } \\
\text { Transformasional } \\
(\text { KT })\end{array}$ & $\begin{array}{c}\text { Komitmen } \\
\text { Organisasi } \\
(\text { KO) }\end{array}$ & $\begin{array}{c}\text { Perilaku } \\
\text { Inovatif } \\
(\text { PI) }\end{array}$ \\
\hline Skor Terendah & 65 & 75 & 77 \\
Skor Tertinggi & 139 & 133 & 142 \\
Jangkauan & 74 & 58 & 65 \\
Rata-rata & 107,90 & 111,18 & 109,45 \\
Standar Deviasi & 16,39 & 14,93 & 15,42 \\
Varians & 268,76 & 222,91 & 237,77 \\
\hline
\end{tabular}

Pengujian hipotesis dilakukan dengan menggunakan koefisien jalur yang hasilnya ditunjukkan pada Tabel 2. Berdasarkan hasil perhitungan dengan LISREL untuk goodness of fit model diperoleh RMSEA sebesar 0,000 dan p-value 1,000. Hasil yang diperoleh menunjukkan RMSEA $<0,08$ dan p-value $>0,05$, sehingga dapat disimpulkan

Tabel 2:

Koefisien Jalur dan t-hitung bahwa model penelitian pengaruh kepemimpinan transformasional terhadap perilaku inovatif yang dimediasi oleh komitmen organisasi memiliki kesesuaian yang baik antara model teoritis dan model empiris.

4. $\mathrm{KT} \rightarrow \mathrm{KO} \rightarrow \mathrm{PI} \quad 0,294$

\begin{tabular}{|c|c|c|c|c|}
\hline No. & Hipotesis & Koefisien Jalur & t-hitung & Keputusan \\
\hline 1. & $\mathrm{KT} \rightarrow \mathrm{PI}$ & 0,414 & \multicolumn{2}{|c|}{ Dari1 hasil perhitungan koefien jalur } \\
\hline 2. & $\mathrm{KO} \rightarrow \mathrm{PI}$ & 0,410 & $\begin{array}{l}\text { In t-hît558 di } \\
\text { ngujian hipotes }\end{array}$ & $\begin{array}{l}\text { AktherdingatilRan hasil } \\
\text { ebagai berikut: }\end{array}$ \\
\hline
\end{tabular}




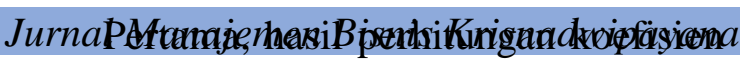
jalur pengaruh langsung kepemimpinan transformasional terhadap perilaku inovatif

( $\left.\mathrm{P}_{\mathrm{Y} 1}\right)$ sebesar 0,414 dan nilai t-hitung adalah 3,597 >t tabel $=1,96$, sehingga Ho ditolak dan mendukung $\mathrm{Ha}$, yang dapat disimpulkan bahwa kepemimpinan transformasional berpengaruh langsung positif terhadap perilaku inovatif.

Kedua, koefisien jalur pengaruh langsung komitmen organisasi terhadap perilaku inovatif $\left(\mathrm{P}_{\mathrm{Y} 2}\right)$ sebesar 0,410 dan nilai t-hitung $=3,558>\mathrm{t}$-tabel $=1,96$, maka tolak Ho, dan mendukung Ha, yang berarti komitmen organisasi berpengaruh langsung positif terhadap perilaku inovatif.

Ketiga, koefisien jalur pengaruh langsung kepemimpinan transformasional terhadap komitmen organisasi $\left(\mathrm{P}_{21}\right)$ sebesar 0,718 dan t-hitung $=8,327>\mathrm{t}$ tabel $=1,96$, sehingga Ho ditolak dan mendukung Ha, yang berarti kepemimpinan transformasional memiliki pengaruh langsung positif terhadap komitmen organisasi.

Keempat, koefisien jalur pengaruh tidak langsung kepemimpinan transformasional terhadap perilaku inovatif melalui komitmen organisasi $\left(\mathrm{P}_{\mathrm{Y} 1.2}\right)$ adalah 0,294 dan nilai $\mathrm{t}$-hitung $=3,272>\mathrm{t}$-tabel $=$ 1,96, sehingga Ho ditolak dan mendukung $\mathrm{Ha}$, yang dapat disimpulkan bahwa komitmen organisasi memediasi pengaruh kepemimpinan transformasional terhadap perilaku inovatif.

\section{Pembahasan}

Hasil penelitian ini menunjukkan bahwa kepemimpinan transformasional mendukung perilaku inovatif Kepemimpinan transformasional menjadi faktor yang sangat penting bagi organisasi karena keterampilan transformasional menjadi sumber inspirasi dan motivasi bagi bawahan dalam bekerja. Hal ini sebagaimana dikemukakan Gibson et al. (2012), bahwa kepemimpinan transformasional berarti kemampuan untuk memberikan inspirasi dan motivasi kepada bawahan agar bersedia mencApdi Kasihtubih

besar dibandingkan perencanaan awal untuk

imbalan internal. Pemimpin transformasional merupakan pemimpin yang mampu membawa perubahan, menanamkan visi, memberikan inspirasi, melakukan stimulasi intelektual dan pengaruh idealisme sehingga dapat membantu bawahan menjadi lebih inovatif. Daft (2010) menjelaskan bahwa pemimpin yang menggunakan kepemimpinan transformasional dapat meningkatkan inovasi organisasi baik secara langsung melalui menciptakan visi maupun dengan menciptakan lingkungan yang mendukung eksplorasi, eksperimen, pengambilan risiko dan berbagi ide. Hasil penelitian Majumdar dan Ray (2011) juga membuktikan bahwa kepemimpinan transformasional mendukung perilaku inovatif.

Selain mendukung perilaku inovaitf, kepemimpinan transformasional juga mendukung komitmen organisasi. Peran penting kepemimpinan transformasional dalam meningkatkan komitmen organisasi karena seorang pemimpin transformasional memiliki kemampuan dan kepedulian serta memotivasi dan mengembangkan karyawan, sehingga pada akhirnya dapat memnimbulkan ikatan yang lebih kuat terhadap organisasinya. Colquitt, LePine, dan Wesson (2013) menjelaskan bahwa kepemimpinan transformasional mendukung komitmen karyawan. Pemimpin yang menerapkan kepemimpinan transformasional cenderung memiliki komitmen afektif dan normatif yang lebih tinggi. Hasil penelitian terdahulu yang dilakukan Atmojo juga membuktikan bahwa kepemimpinan transformasional mendukung komitmen organisasi.

Penelitian ini juga menunjukkan bahwa komitmen organisasi berperan penting dalam mendorong perilaku inovatif. Terkait dengan hal itu Lee (2008) menjelaskan peran penting komitmen organisasi terhadap perilaku inovatif, dimana komitmen organisasi telah memiliki sifat alamiah sebagai kunci dalam meningkatkan perilaku inovatif karyawan. Wenhua (2011) juga mengungkapkan 
Jurnal Manajemen Bisnis Krisnadwipayana bahwa komitmen organisasi mendukung perilaku inovatif. Aspek komitmen organisasi yang berperan penting dalam meningkatkan perilaku inovatif terutama adalah komitmen afektif dan komitmen kontinuasi. Hasil penelitian terdahulu yang dilakukan Malik, Javed, dan Hassan (2017) juga menemukan bahwa komitmen afektif mendukung perilaku inovatif.

Hasil penelitian ini juga menunjukkan komitmen organisasi berperan sebagai variabel mediator mendukung kepemimpinan transformasional terhadap perilaku inovatif. Temuan ini menunjukkan bahwa kepemimpinan transformasional akan mendukung komitmen organisasi dan selanjutnya akan meningkatkan perilaku inovatif. Hasil yang demikian tidak terlepas dari temuan sebelumnya yang menunjukkan kepemimpinan transformasional mendukung komitmen organisasi dan komitmen organisasi mendukung perilaku inovatif. Arah dukungan yang demikian memungkinkan terjadinya dukungan tidak langsung atau dukungan mediasi kepemimpinan transformasional terhadap perilaku inovatif melalui komitmen organisasi.

\section{KESIMPULAN DAN SARAN}

\section{Kesimpulan}

Kesimpulan dalam penelitian ini menunjukkan, 1). Kepemimpinan transformasional mendukung perilaku inovatif. 2). Komitmen organisasi mendukung perilaku inovatif tenaga pemasaran. 3). Kepemimpinan transformasional mendukung komitmen organisasi tenaga pemasaran. 4). komitmen organisasi berperan sebagai variabel mediator mendukung kepemimpinan transformasional terhadap perilaku inovatif.

\section{Saran}

Saran dari hasil penelitian ini yaitu perlunya mengembangkan kemampuan pimpinan untuk menerapkan kepemimpinan transformasional. Kapasitas yang perlu dikembangkan terutama adalah cara-cara memotivasi dan menginspirasi para tenaga pemasaran sehingga dapat This work is licensed under a Creative Commons Attribution-NonCommercial-ShareAlike 4.0 International License. Ciptaan disebarluaskan di bawah Lisensi Creative Commons Atribusi-BerbagiSerupa 4.0 Internasional. memberikan pengaruh sAcrdiaKusefielkcif terhadap tenaga pemasaran dalam melakukan perubahan- perubahan ke arah positif dalam melaksanakan tugasnya sebagai tenaga pemasaran. Komitmen organisasi tenaga pemasaran juga perlu diperkuat dengan cara membangun nilainilai dan tujuan organisasi yang menarik dan bermanfaat serta realistis untuk diwujudkan agar terbangun ikatan emosional yang kuat antara perusahaan dengan tenaga pemasaran.

\section{DAFTAR PUSTAKA}

Acar, A. Z., \& Acar, P. 2012. The Effects of Organizational Culture and Innovativeness on Business Performance in Healthcare Industry. Procedia - Social and Behavioral Sciences, $\quad 58, \quad 683-692$. https://doi.org/10.1016/j.sbspro.2012.

09.1046

Armstrong, M. 2009. A Handbook of Human Resource Management Practice. London, Philadelphia: Kogan Page.

Bertocci, D. I. 2009. Leadership in Organizations: There Is a Difference between Leaders and Managers. Maryland: University Press of America, Inc.

Carmeli, A., \& Spreiter, G. M. 2009. Trust, Connectivity, and Thriving: Implications for Innovative Behaviors at Work. Journal of Creative Behavior, 43(3), 169-191. https://doi.org/10.1002/j.21626057.2009.tb01313.x

Cingöz, A. \& Akdogan, A. A. 2011. “An empirical examination of performance and image outcome expectation as determinants of innovative behavior in the workplace. Procedia Social and Behavioral Sciences, Vol. 24, 847853.

Colquitt, Jason A., Lepine, Jeffrey A. \& Wesson, Michael J. 2013. Organizational Behavior. New York: McGraw-Hill. 
J. H. \& Kanopaske, R. 2012. Organizations: Behavior, Structure, Processes. New York: McGraw-Hill Companies, Inc..

Griffin, R. W. \& Moorhead, G. 2014. Organizational Behavior: Managing People and Organizations. Mason: South-Western, Cengage Learning.

Hitt, M. A., Miller, C. C. \& Colella, A. 2011. Organizational Behavior. New Jersey: John Wiley \& Sons, Inc.

Kleysen, R. F. \& Street, C. T. 2001. "Toward a multi-dimensional measure of individual innovative behavior. Journal of Intelectual Capital, Vol. 2, No. 3, 284-296.

Lee, O. F., Tan, J. A. dan Javalgi, R. “Goal Orientation and Organizational Commitment: Individual Difference Predictors of Job Performance. International Journal of Organizational Analysis, Vol. 18 No. 1, 2010, 129-150.

Levy, P. E. Industrial/Organizational Psychology: Understanding the Workplace. New York: Worth Publishers, 2010.

Majumdar, B. dan Ray, A. 2011. "Transformational Leadership and Innovative Work Behaviour". Journal of the Indian Academy of Applied Psychology, Vol. 37, No.1, 140-148.

Malik, W. U., Javed, M., Hassan, S. T. 2017. "Influence of transformational leadership components on job satisfaction and organizational commitment", Pakistan Journal of Commerce and Social Sciences (PJCSS), Vol. 11, Iss. 1, pp. 147-166.

Muchinsky, P. M. 2006. Psychology Applied to Work. Belmont CA:
Muhammad Farhan; Muhammad Faisal. 2021. "Krisnadwipayana International Journal of Management Studies." Krisnadwipayana International Journal of Management Studies 1(1): 33-44

Park, S., \& Jo, S. J. 2018. The impact of proactivity, leader-member exchange, and climate for innovation on innovative behavior in the Korean government sector. Leadership \& Organization Development Journal, 39(1),130-149. https://doi.org/10.1108/LODJ-092016-0216

Pedraza, C. G., Bravo, E. R., Olivera, H. \& Blanco, F. 2012. Innovation in Service Firms: Perspective From Innovative Behavior, eds. Fernando Chaparro. Bogota: Universidad Del Rosario.

Rowe, W. G. \& Guerrero, L. 2011. Cases in Leadership. California: SAGE Publications, Inc., 2011.

Shih, Hsi-An \& Susanto, E. 2011. "Is innovative behavior really good for the firm?: Innovative work behavior, conflict with coworkers and turnover intention: moderating roles of perceived distributive fairness. International Journal of Conflict Management, Vol. 22 Iss: 2, 111 130.Tidd, J., Bessant, J., \& Pavitt, K. (2005). Managing Innovation: Integrating Organizational Change. Chichester: John Wiley \& Sons, Inc.

Wenhua, W. "Empirical research on knowledge employees' organizational commitment and innovative behavior in high-tech enterprises". International Conference on EBusiness and EGovernment ICEE,2011, 1-4 
